\title{
PERBANDINGAN HASIL BELAJAR DAN MOTIVASI SISWA ANTARA KELAS YANG MENGGUNAKAN KOOPERATIF TIPE THINK PAIR SQUARE (TPSq) DENGAN KOOPERATIF TIPE THINK PAIR SHARE (TPS) PADA MATERI FOTOSINTESIS KELAS VIII DI SMP N 19 PEKANBARU
}

\author{
Iqbal Febrian ${ }^{1)}$, Raudhah $\mathrm{Awal}^{2)}$ \\ 1) 2) Pendidikan Biologi FKIP Universitas Lancang Kuning \\ email $^{1)}$ :febrianiqbal14@gmail.com \\ email ${ }^{2}$ :raudhahawal@unilak.ac.id
}

\begin{abstract}
ABSTRAK: Desain penelitian yang digunakan adalah weak experiment dengan desain the static-grup pretest-posttest desaign. Sampel penelitian adalah siswa kelas VIII3 dengan jumlah siswa 29 orang dan VIII4 dengan jumlah siswa 30 orang. Pengambilan sampel dilakukan dengan menggunakan teknik simple random sampling. Pengumpulan data dilakukan melalui pretest, posttest, angket motivasi dan lembar observasi aktivitas guru dan siswa. hasil data uji-t N-Gain adalah $0.014<0.05$ (a), maka tolak $\mathrm{H}_{0}$ yang artinya terdapat perbedaan signifikan antara $\mathrm{N}$-Gain kelas TPS dan kelas TPSq. Hal ini juga dapat dilihat pada rerata N-Gain kelas TPS 0.59, sedangkan pada kelas TPSq 0.68. dan motivasi belajar siswa di kelas TPS dan TPSq didapatkan hasil posttest yang telah di analisis dengan menggunakan uji-t sig (2 tailed) adalah $0.026<0.05$ keputusan yang di ambil adalah tolah $\mathrm{H}_{0}$ yang artinya pada kelas TPS dan TPSq terdapat perbedaan siknifikan, yang artinya siswa pada kelas TPS dan TPSq memiliki motivasi yang berbeda. Berdasarkan hasil penelitian ini dapat disimpulkan bahwa terdapat perbedaan hasil belajar dan motivasi siswa antara kelas yang menggunakan kooperatif tipe Think Pair Square (TPSq) dengan kooperatif tipe Think Pair Share (TPS) pada materi fotosintesis kelas VIII SMP 19 Pekanbaru Tahun Ajaran 2018/2019.
\end{abstract}

Kata Kunci: Think Pair Square, Think Pair Share, hasil belajar siswa

ABSTRACT: The research design used was weak experiment with design of the static group design pretest-posttest. Sample of this stady was students of class VIII3 with a total of 29 students and VIII4 with 30 students. Sampling is taken by using simple random sampling technique. Data collection was done through pretest, posttest, motivation questionnaire and observation sheets of teacher and student activities. The results of the $N$-Gain t-test data are $0.014<0.05(a)$, which means there are significant differences between Think Pair Square (TPSq) class and Think Pair Share (TPS) class at photosintesis sabject. This can also be seen in the average of $N$-Gain while N-Gain TPS class are 0,59 and TPSq class are 0,68. Students' learning 
motivation in TPS and TPSq classes obtained the posttest results that have been analyzed using the t-test sig ( 2 tailed) is $0.000<0.05$ which means that there are significant differences between TPS and TPSq class, so that students in TPS and TPSq classes have different motivations. Based on the results of this study it can be concluded that there are differences in learning outcomes and motivation of students between Think Pair Square (TPSq) class and Think Pair Share (TPS) class at photosintesis subject class VIII SMP N 19 Pekanbaru.

Keywords: Think Pair Square, Think Pair Share, student's achievement.

\section{PENDAHULUAN}

\section{A. Latar Belakang}

Penelitian tentang penggunaan model pembelajaran kooperatif pernah dilakukan oleh Surayya, et al. (2014) yang berjudul pengaruh model pembelajaran think pair share terhadap hasil belajar IPA ditinjau dari keterampilan berpikir keritis siswa Hasil penelitian menunjukkan bahwa terdapat perbedaan hasil belajar antara siswa yang mengikuti model pembelajaran TPS dengan siswa yang mengikuti model pembelajaran konvesional. Berdasarkan hasil penelitian ini dapat direkomendasikan bahwa model pembelajaran TPS dapat digunakan sebagai alternatif model pembelajaran untuk meningkatkan hasil belajar IPA.

Berdasarkan hasil observasi dan wawancara yang dilakukan di SMPN
19 Pekanbaru pada materi Fotosintesis, pada tahun ajaran 2016/2017 diketahui bahwa masih banyak siswa yang kurang memperhatikan penjelasan guru pada saat guru menyampaikan materi dan siswa kurang memiliki motivasi dalam belajar. Hal ini dibuktikan dengan tingkah laku siswa yang malas belajar dan kurang menyampaikan pendapat ataupun bertanya. Siswa lebih cenderung diam dan tidak semangat dalam menerima materi dalam proses pembelajaran. Hal ini disebabkan metode yang digunakan oleh guru yaitu metode konvensional (ceramah atau diskusi), sehingga kurang menarik bagi siswa dan juga berdampak terhadap motivasi belajar siswa itu sendiri. 


\section{METODE PENELITIAN}

Penelitian ini merupakan weak experiment dengan desain the staticgrup pretest posttest design, mengelolah kondisi perlakuan pada suatu kelompok, dan memberinya, posttest.

Populasi dalam penelitian ini adalah seluruh siswa kelas VIII SMP N 19 pekanbaru tahun ajaran 2017/2018 yang terdiri dari 4 kelas paralel dengan jumlah siswa 135 orang. Sampel penelitian dari 2 kelas yang diambil dengan menggunakan teknik simpel random sampling, sehingga didapat kelas sampel adalah VIII.3 dan VIII.4. Kelas VIII.3 Berjumlah 30 orang dan kelas VIII.4 berjumlah 30 orang.

Parameter yang digunakan dalam penelitian ini adalah : Hasil belajar siswa yang meliputi kemampuan kognitif pretest dan posttest. Motivasi siswa dengan indikator : Adanya hasrat keinginan berhasil, adanya dorongan dan kebutuhan dalam belajar, adanya harapan dan cita-cita masa depan, adanya penghargaan dalam belajar, adanya kegiatan yang menarik dalam belajar dan adanya lingkungan belajar yang kondusif. Aktivitas belajar siswa. Aktivitas guru

\section{HASIL DAN PEMBAHASAN}

\section{A. Hasil Penelitian}

Berdasarkan analisis data yang dilakukan di temukan rerata pretest kelas TPS adalah 50,80 dan pretest untuk kelas TPSq adalah 52,33 hasil uji-t terhadap data tersebut menunjukkan nilai $\alpha$ adalah $0.473>$ 0.05 keputusan yang di ambil adalah terima $\mathrm{H}_{0}$ yang artinya bahwa pada kelas TPS dan kelas TPSq tidak terdapat perbedaan yang signifikan, yang artinya siswa pada kelas TPS dan TPSq memiliki pengetahuan awal yang sama pada materi fotosintesis, ini di sebabkan oleh siswa pada kelas TPS dan TPSq siswa hanya mengetahui materi fotosintesis di tingkat dasar yaitu pada saat SD sehingga pengetahuan dasar yang di dapat oleh siswa sama.

Dari hasil analisis data motivasi yang dilakukan ditemukan nilai rerata pretest kelas TPS adalah 3,21 dan pretest kelas TPSq adalah 2,49 hasil uji-t terhadap data tersebut menunjukkan nilai $\alpha$ adalah $0.000<$ 0.05 keputusan yang di ambil adalah 
tolah $\mathrm{H}_{0}$ yang artinya pada kelas TPS dan TPSq terdapat perbedaan siknifikan, yang artinya siswa pada kelas TPS dan TPSq memiliki motivasi yang berbeda, ini di sebabkan karena siswa pada kelas TPS dan TPSq belum paham maksud dan tujuan belajar secara merata.

Berdasarkan analisis data yang dilakukan di temukan rerata posttest kelas TPS adalah 79,54 dan posttest untuk kelas TPSq adalah 85,33 tingginya rerata posttest kelas TPSq di bandingkan kelas TPS disebabkan karena model pembelajaran kelas TPSq adalah model pembelajaran kelompok yang terdiri dari 4 orang siswa, sehingga lebih banyak pemikiran yang tertuang didalam kelompok menjadi satu fikiran bersama sehingga siswa memiliki pengetahuan dan hasil yang lebih tinggi dari pada siswa yang menggunakan model pembelajaran TPS, hal ini di dukung oleh penelitian Utami, et al (2004) diperoleh hasil bahwa model pembelajaran TPSq mampu miningkatkan perkembangan penalaran pada siswa dalam pembelajaran. Sedangkan hasil uji-t terhadap data posttest menunjukkan nilai $\alpha$ adalah $0.006<0.05$ keputusan yang di ambil adalah tolak $\mathrm{H}_{0}$ yang artinya bahwa pada kelas TPS dan kelas TPSq terdapat perbedaan yang signifikan, yang artinya siswa pada kelas TPS dan TPSq memiliki hasil belajar yang berbeda pada materi fotosintesis, ini di sebabkan oleh siswa pada kelas TPS dan TPSq sudah mendapatkan model pembelajaran yang berbeda pada masing masing kelasnya dan dengan dibaginya kelompok siswa dapat mengembangkan apa yang telah di pelajari di dalam kelompok nya masing masing sehingga pengetahuan yang di miliki siswa dapat berbeda pula dengan gaya berfikir mereka masing-masing. Hal ini sejalan denagan penelitan yang dlakukan Tahueyo et al (2012) yaitu dilihat dari rata-rata hasil belajar medel think pair square lebih beaik dengan hasil belajar lebih tinggi.

Dari hasil analisis data $N$ gain yang dilakukan ditemukan nilai rerata kelas TPS adalah 0,59 dan pretest kelas TPSq adalah 0,68, hal ini didukung dengan kenyataan bahwa hasil belajar dari dua 
pertemuan yang dilakukan selama penelitan menunjukan bahwa peningkatan hasil belajar siswa dari kelas TPSq selama proses pembelajaran lebih tinggi dari kelas TPS, dengan rata-rata peningkatan hasil belajar siswa pada kelas TPSq dan TPS berbeda siknifikan, pernyataan ini di dukung oleh penelitian Pakpahan, et al (2004), yaitu terdapat peningkatan yang siknifikan terhadap siswa dengan menggunakan model pembelajaran TPSq, dan hasil analisis nilai $\mathrm{N}$-gain dengan menggunakan uji hipotesis komparati yaitu uji-t (2 tailed) adalah $0.014<0,05$ keputusan yang di ambil adalah tolak $\mathrm{H}_{0}$ artinya terdapat perbedaan siknifikan antara kelas yang menggunakan model pembelajran TPS dengan kelas yang menggunakan model pembelajaran TPSq, perbedaan yang siknifikan ini di sebabkan oleh perbedaan model pembelajaran yang diterapkan sehingga dapat berpengaruh terhadapa perbedaan hasil pembelajaran dari kelas TPS dengan TPSq.ini sesuai dengan penelitain yang dilakukan Antosa et al (2014) didapatkan bahwa hasil belajar matematika siswa mengalami peningkatan setelah menggunakan model pembelejaran kooperatif tipe Think Pair Square.

Dari hasil analisis data motivasi yang dilakukan ditemukan nilai rerata posttest kelas TPS adalah 3,23 dan pretest kelas TPSq adalah 3,31 dapat dilihat rerata posttes motivasi siswa pada kelas TPS lebih tinggi dari kelas TPSq, ini sesuai dengan pendapat Uno (2008) bahwa motivasi adalah dorongan dasar yang menggerakkan seseorang bertingkah laku. Sedangkan hasil uji-t terhadap data tersebut menunjukkan nilai $\alpha$ adalah $0.026<0.05$ keputusan yang di ambil adalah tolah $\mathrm{H}_{0}$ yang artinya pada kelas TPS dan TPSq terdapat perbedaan siknifikan, yang artinya siswa pada kelas TPS dan TPSq memiliki motivasi yang berbeda, ini di sebabkan karena siswa pada kelas TPS dan TPSq sudah mendapatkan pembelajaran yang berbeda dalam kelasnya sehingga motivasi yang di dapati berbeda karena pola pikir yang berbeda pula pada setiap siswa di dalam kelasnya. ini sesuai denan pendapat Terry (2005) Motivasi ialah keinginan yang terdapat dalam diri 
seseorang individu yang merangsang untuk melakukan tindakan-tindakan.

Tingginya peningnkatan hasil belajar dan motivasis siswa di kelas TPSq dari pada kelas TPS juga ada pengaruhnya dengan Rerata aktivitas siswa di mana rerata keseluruhan kelas TPSq lebih tinggi dari pada rerata kelas TPS yaitu pada kelas TPSq adalah 91,31 \% sedangkan rerata keseluruhan aktifitas kelas TPS adalah 89,99\%.

Observasi aktivitas siswa yang diamati pada kelas TPS pertemuan I dengan rerata $87,24 \%$ pada pertemuan II dengan rerata persentase $90,34 \%$. Observasi siswa kelas TPSq pada pertemuan I dengan jumlah rerata persentase sebesar $88,66 \%$ dan pada pertemuan II dengan jumlah rerata persentase sebesar 93,99\% . dapat disimpulkan bahwa aktivitas siswa dari pertemuan I dan pertemuan II meningkat. Hal ini disebabkan karena Penggunan mode pembrlajaran TPS dan TPSq pada masing masing kelasnya sehingga mendorong siswa untuk meningkatkan keaktifan, kemandirian, tanggung jawab serta siswa akan terfokus pada guru dan kawan kawan satu keasnya menampilkan hasil kelompok mereka. Sehingga siswa menjadi mempunyai keberanian untuk menyampaikan hasil kerjanya dan membantu siswa untuk aktif dalam kegiatan pembelajaran, meningkatkan kemampuan siswa dalam berkomunikasi (aspek berbicara). Penelitian ini sejalan dengan penelitian yang dilakukan oleh.

Pada uraian diatas dapat dilihat bahwa tahap-tahap pembelajaran yang dilaksanakan oleh guru, baik untuk kelas TPS maupun kelas TPSq berjalan dengan lancar sesuai dengan yang diharapkan. Namun hasil belajar tetap berbeda, yaitu pada kelas TPS lebih rendah dibandingkan dengan kelas TPSq. Hal ini disebabkan karena pada kelas TPS proses pembelajaran yang digunakan yaitu hanya menggunakan 1 kelompok yang terdiri hanya dari 2 orang siswa sehingga mengurangi hasil yang didapatkan siswa. Sedangkan pada kelas TPSq setelah kita bagi dalam kelompok mereka di gabung 


\section{KESIMPULAN DAN SARAN}

\section{A. Kesimpulan}

Berdasarkan hasil penelitian yang $\begin{array}{lllll}\text { telah dilakukan } & \text { di } & \text { SNP } & \text { N } & 19\end{array}$ Pekanbaru dapat diambil kesimpulan bahwa terdapat perbedaan hasil belajar siswa antara kelas yang menerapkan TPS dengan kelas yang menerapkan model pembelajaran TPSq, Kelas yang menerapkan pembelajaran TPSq lebih meningkat dari kelas yang menggunakan model pembelajaran TPS. Kemudian untuk data primer angket motivasi belajar siswa terdapat perbedaan pula pada

jawaban responden, kelas yang menerapkan model pebelajaran TPSq lebih meningkat dari kelas yang menggunakan model pembelajaran TPS. Rerata aktivitas siswa TPS pada pertemuan I, II adalah $88,79 \%$. Dan TPSq pertemuan I,II adalah 91,32\%. Peningkatan aktivitas siswa kelas TPS dan TPSq juga dipengaruhi oleh aktivitas guru, aktivitas guru kelas TPS pada pertemuan I, II adalah $90 \%$ dan TPSq pertemuan I,II adalah 90\%.

\section{B. Saran}

Berdasarkan hasil penelitian yang telah penulis lakukan, maka penulis menyampaikan saran sebagai berikut: Disarankan pembelajaran TPSq dapat dijadikan alternatif pembelajaran bagi guru dalam rangka menambah variasi model beajar untuk meningkatkan hasil belajar siswa. Dalam penerapan mode pembelajaran TPSq sebagai guru

harus menguasai kelas agar tidak ribut saat pelajaran berlangsung dan pada saat pembagian kelompok. Dalam pembelajaran TPS pertimbangkan waktu pada saat presentase kelompok. guru dapat mengambangkan lagi pola

fikir siswa menggunakan model pembelajaran TPSq dan menjadikan pembelajaran lebih efektif serta meningkatkan guru 
dalam kegiatan belajar mengajar (KBM).bagi peneliti yang ingin melanjutkan atau melaksanakan perbandingan pembelajaran TPS

\section{DAFTAR PUSTAKA}

Arikunto, S. (2014). Dasar-dasar Rvaluasi Pendidikan. Bumi Aksar: Jakarta.

Cooper, James L. \& Pamela Robinson,(2000) Getting Started: Informal SmallGroup Strategies in Large Classes, New direction for teaching and learning, no. 81.

Dimyanti dan Mudjiono. (2006). Belajar dan Pembelajaran. Jakarta

Franklen, J. R dan Wallen, N. E. (2009). How to Design and Evaluate Research In Education: Singapore.

Hamalik, O . (2002). Psikologi Belajar Mengajar. Sinar Baru Al: Bandung.

Hardini, I dan Puspitasari, D. (2012). Strategi Pembelajaran Terpadu. Familia: Yogyakarta.

Iriyanto. H. D. (2012). Learning Metamorphosis Hebat Gurunya Dahsyat Muridnya. Erlangga: Jakarta

Kunandar. (2010). Langkah Mudah Penelitian Tindakan Kelas Sebagai Pengembangan Profesi Guru. PT Raja Grafindo Persada: Jakarta. dan TPSq, sebagai memilih materi yang pas untuk model pembeajaran TPS dan TPSq.

Lie, A. (2010). Cooperatif Learning (Mempraktekkan Cooperative Learning di Ruang Kelas). PT Grasindo: Jakarta.

Meltzer, D. E. (2002). Relation Between Matematics Preparation and Conceptual Learning Gains In Physicn: A Possible "Hidden Variabel" In Diagnostic Pretest Score. American Journal Of Physics. Vol 70 No. 12 Hal: 12591269.

Pakpahan, et al, (2015). Pengaruh Penerapan Model Pembelajaran Kooperatif Tipe Think Pair Share (Tps) Terhadap Peningkatan Kemampuan Pemahaman Matematis Siswa Kelas X Mia Man 1 Pekanbaru. eJournal. Vol 3. No1. Hal 114.

Purwanto. (2009). Evaluasi Hasil Belajar. Pustaka Belajar: Surakarta.

Sanjaya, W. (2009). Strategi Pembelajaran Berorientasi Standar Proses Pendidikan. Prenada: Jakarta.

Santrock, J. W. (2008). Psikologi Pendidikan. Prenada Media Group: Jakarta 
Sardiman, A. M. (2004). Interaksi dan Motivasi belajar Mengajar. Raja Drafindo, Persada: Jakarta.

Slameto. (2010). Belajar dan Faktorfaktor yang Mempengaruhi. Rineka cipta: Jakarta.

Starr. C, et al. (2012). Biologi Edisi 12 Buku 1 Kesatuan dan Keragaman Makhluk Hidup. Salemba Teknika: Jakarta.

Sudjana. (2008). Penilaian Hasil Proses Belajar Mengajar. Remaja Rosdakarya: Bandung.

Sugiyono. (2009). Statistik Untuk Penelitian. Alfabeta: Bandung

Sumaryati dan Sumarmo. (2013). Pendekatan Induktif-Deduktif Disertai Strategi Think-PairSquare-Share Untuk Meningkatkan Kemampuan Pemahaman Dan Berpikir Kritis Serta Disposisi Matematis Siswa Sma. infinity. Vol 2. No 1. Hal 2642.

Surayya, et al. (2014). Pengaruh model pembelajaran Think pair share terhadaphasil belajar ipa ditinjau dari keterampilan berpikir keritis siswa. e-Journal. Vol 4. No 1. Hal 1-11.

Tahueyo, et al. (2012). Penerapan Model Kooperatif Tipe ThinkPair-Square Dalam Pembelajaran Fisika Kelas Ix
Smp Batara Gowa. E-journal. Vol 1. No 2. Hal 95-107

Uno, H. B. (2008). Teori Motivasi dan Pengukurannya. Bumi Aksara: Jakarta. 